\title{
The use of precision farming technologies in the cultivation of winter wheat in the conditions of the Orel region
}

\author{
Svetlana Konoshina ${ }^{1}$, Ivan Konoshin ${ }^{1}$, Elena Prudnikova $^{1}{ }^{*}$, and Natalia Makarova ${ }^{2}$ \\ ${ }^{1}$ Orel State Agrarian University named after N. V. Parahin, 69, Generala Rodina St., Orel, \\ 302019, Russian Federation \\ ${ }^{2}$ FSBEI HE Orel State University named after I.S. Turgenev, 95, Komsomolskaya Str., Orel, \\ 302026, Russian Federation
}

\begin{abstract}
The analysis of the use of precision farming systems for the cultivation of winter wheat of the Moskovskaya 39 variety in the climatic and soil conditions of the Orel region of the Russian Federation is carried out. The value of the vegetation index NDVI was used as a reference indicator for determining the amount of macronutrients introduced. The effect of applied fertilizers on winter wheat plants was found to be stimulating for their targeted distribution. The application of fertilizers without taking into account the needs for this site led to uneven plant development, lodging, a decrease in yield and an increase in the cost of production.
\end{abstract}

\section{Introduction}

Rational use of agricultural land in the Russian Federation has always been relevant. Effective use of land resources is impossible without the development and application of resource-saving technologies in economic activities [1,2].

Resource saving in agricultural production refers to the technology of obtaining the maximum amount of high-quality products at the lowest cost. Such a result is impossible without optimal use of both the biological resource of the agricultural crop and the soil resources, taking into account climatic conditions $[3,4]$. The introduction of macro and microelements has a special role in agricultural technology $[5,6]$.

The agro-industrial complex of the Orel region allows to produce products not only for domestic needs, but also for its sale outside the region. The effective use of all means and methods in the cultivation of agricultural products will allow to get the best result.

The world industry produces a wide variety of technical means for agricultural purposes, the competent use of which allows enterprises to get maximum profit.

The purpose of this work is to analyze the use of resource-saving technologies using modern technical means in the Orel region.

\footnotetext{
* Corresponding author: elena-prudnikova00@ rambler.ru
} 
The combination of ground-based and aerospace methods for obtaining heterogeneous information about agricultural fields is optimal when using precision farming equipment.

Precision farming considers each field as a heterogeneous area in terms of terrain, nutrition elements, and moisture supply, and differentiated farming technologies are developed for each such area $[7,8]$.

The Orel region, where more than 110 farms operate under the precision farming system, ranks second among the regions of the Russia in this area.

\section{Material and methods}

To study the effect of precise fertilizer distribution on the physiological activity of agricultural plants and their yield on podzolic chernozems of the Orel region, Amazone TS fertilizer spreaders were used. These spreaders are equipped with Section Control systems together with GPS-Switch and GPS-Track navigation function, as well as the Argus Twin sensor system for monitoring the lateral distribution of fertilizer and the Wind Control function for monitoring and adjusting the distribution of fertilizers in windy weather.

The research was conducted in winter wheat fields in two thousand twentieth year. The soils on which the experiments were laid have an acidity close to neutral acidity (the $\mathrm{pH}$ of the salt extract is $5.9-6.1$ ), have an increased content of mobile phosphorus (from 12.6 to $13.8 \mathrm{mg} / 100 \mathrm{~g}$ of soil) and a high content of exchangeable potassium (varies in the range of $19.3-20.4 \mathrm{mg} / 100 \mathrm{~g}$ of soil), are moderately provided with humus (4.3 - $4.8 \%$ ).

Total absorbed bases in the studied areas is $27.1 \mathrm{mg}$-eq per $100 \mathrm{~g}$ of soil, the content of exchangeable calcium is $25.1-25.3 \mathrm{mg}$-eq per $100 \mathrm{~g}$ of soil, the content of exchangeable magnesium is $4.15-2.1 \mathrm{mg}$-eq per $100 \mathrm{~g}$ of soil. Therefore, the soil is suitable for carrying out the planned research on it.

The winter wheat variety Moskovskaya 39 was used as the study crop. The cultivation of the crop and the application of fertilizers were carried out according to the technology recommended for winter wheat.

The field with an area of 150 hectares was conditionally divided into 2 plots (A and B) with approximately the same agrochemical indicators and terrain. Since the beginning of the growing season, fertilizing of plot A was carried out using precision farming techniques, fertilizing of plot B was carried out in the traditional way, without taking into account the NDVI index.

The process of photosynthesis is an indicator of the availability of the necessary elements of agricultural plants [9, 10]. To determine the amount of photosynthetically active biomass, the Normalized Difference Vegetation Index (NDVI) was calculated using the OneSoil web application.

The index is calculated from the absorption and reflection of red and near-infrared rays by plants using the formula

$$
N D V I=\frac{N I R-R E D}{N I R+R E D}
$$

where, NIR - reflection in the near-infrared region of the spectrum, RED - reflection in the red region of the spectrum.

Based on this mathematical expression, the density of the vegetation cover in these coordinates is directly proportional to the difference between the intensity of the reflected color in the red and infrared ranges and inversely proportional to the sum of their intensity. The design of the Amazone TS fertilizer spreaders allows applying fertilizers according to the task card, depending on the content of macronutrients in a particular field area. After conducting a chemical analysis of the soil composition with reference to GPS coordinates, as well as having satellite images with reference to the NDVI index, a special software 
product was used to create a file - a task card, which subsequently distributes fertilizers across the field in accordance with the received task. At the same time, the spreader precisely maintains the set rate due to the presence of weight sensors. The Section Control system, together with the GPS-Switch and the GPS-Track navigation function, allows eliminating double overlap or omissions when applying fertilizers, and to turn off and turn on the distribution on the turn lane in time.

To achieve maximum efficiency, the spreader is equipped with the Argus Twin system, which continuously monitors the distribution of fertilizers using sensors in accordance with the received task and automatically adjusts the operation of the machine to the specified distribution parameters if the parameters are violated.

When applying fertilizers in windy weather, they can be blown away, to reduce the influence of this factor on the uniformity of distribution, the Wind Control function is activated, which, taking into account the direction and strength of the wind, automatically reconfigures the machine and thereby eliminates the influence of wind loads.

\section{Results and discussion}

At the beginning of the growing season, the value of the NDVI index at the control points of the study averaged $0.15-0.21$ in both parts A and B (Figure 1), which is a low indicator of the vegetative development of wheat plants. Fertilizing plants with nitrogen fertilizers at the beginning of the spring growing season in part A of the field was carried out taking into account the NDVI index, and in part B it was carried out in the usual way.

When applying fertilizers, it was taken into account that areas with a high vegetation index value are more provided with nitrogen, so its amount was reduced by 10 percent.

In the beginning of May, the NDVI index in part A had a value in the range of 0.350.47 , and in part B $0.25-0.50$ (Fig. 2, a). In the second case, the fluctuations in the vegetation index were higher, due to the uneven supply of plants with minerals, and, consequently, the uneven development of winter wheat plants. The vegetation zone in both plots was defined as medium and high.

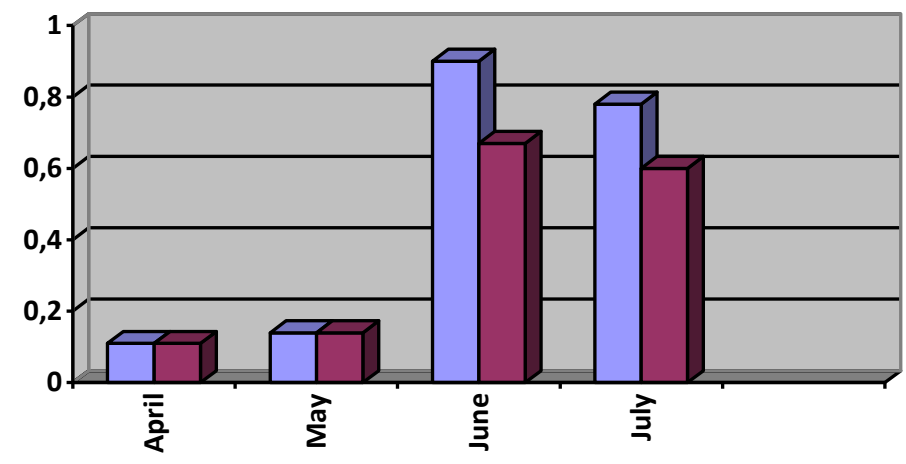

$\square$ part A
$\square$ part B

Fig. 1. Change in the NDVI index in the growing season of 2020.

In mid-June, the vegetation index in part $\mathrm{A}$ of the field was more than 0.85 , and its fluctuations were in the range of 0.84-0.89. The vegetation zone was defined as high. Whereas the plants of the second part of the experimental field had an index of 0.67-0.60. (Figure 2, b) 

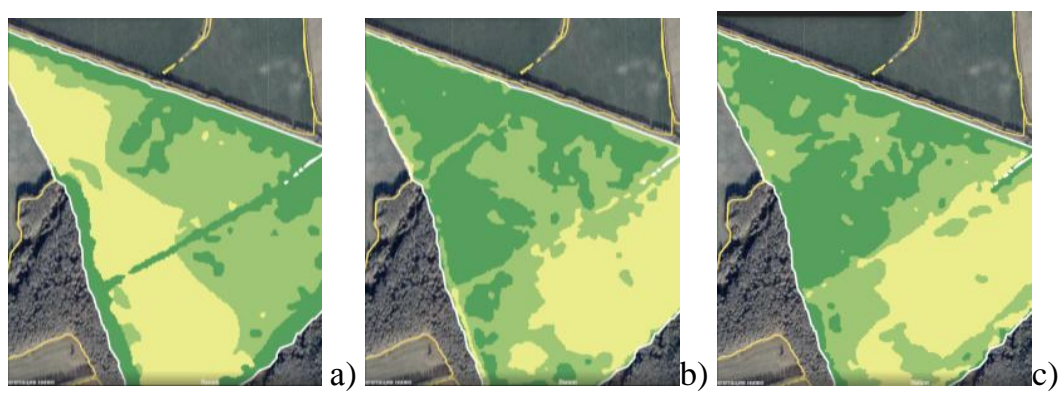

Fig. 2. Vegetation zones of the beginning (a), middle (b) and end of the growing season (c).

The same trend continued in mid-July (Figure 2, b). The value of the vegetation index in plot A was from 0.75 to 0.78 , and in plot B it was from 0.61 to 0.63 . The use of a fertilizer spreader with a constant rate of application and without the use of the above systems led to the lodging of plants on the turn lane, which was observed in some places inside the field, too. The presence of lodged grain negatively affected the speed of grain ripening, as well as reduced the rate of harvesting and led to additional losses for the combine harvester.

The yield of winter wheat on plot A with the use of precision farming technologies was $56.6 \mathrm{c} / \mathrm{ha}$, and that on plot B with the traditional fertilization system was $50.4 \mathrm{c} /$ ha. The consumption of mineral fertilizers on plot $\mathrm{B}$ was $13 \%$ higher than that on plot $\mathrm{A}$.

\section{Conclusions}

The vegetation index NDVI allows assessing the state of the vegetative mass of winter wheat plants.

Application of fertilizers with the help of precision farming technologies makes it possible to align the development of plants on the cultivated area.

The use of macronutrients without taking into account the vegetation index, all other things being equal, leads to uneven plant development and grain ripening, causes lodging, leading to the loss of about eleven percent of the harvest of winter wheat of the Moskovskaya 39 variety.

The savings of fertilizers with targeted application, taking into account the vegetation index, amounted to $13 \%$.

\section{References}

1. Y. Akhtman, E. Golubeva, O. Tutubalina, M. Zimin, Application of hyperspectural images and ground data for precision farming. Geography, environment, sustainability 10(4), 117-128 (2017)

2. T. Schieffer, T. Dillon, Precision agriculture and agro-environmental policy, in: Precision agriculture '13, Ed Stafford J., Wageningen Academic Publishers, 347 (2013)

3. S. Knight, P. Miller, J. Orson, An up-to-date cost/benefit analysis of precision farming techniques to guide growers of cereals and oilseeds. HGCA Research Review, 71, 115 (2009)

4. F.J. Pierce, P. Nowak, Aspects of Precision Agriculture. Adv Agron 1999, 67, 1-86. (1999) 
5. K. Blankenau, H.-W. Olfs, H. Kuhlmann Strategies to improve the use efficiency of mineral fertilizer nitrogen applied to winter wheat. Journal of agronomy and crop science 188, 3, 146-154 (2002)

6. V.T. Lobkov, S.N. Konoshina, Allelopathic soil properties as a factor of fertility. Agricultural biology. 39, 3, 67-71 (2004)

7. H. Heege, Precision in crop farming, Springer, Dordrecht, 356 (2013)

8. T. Griffin, R. Bongiovanni, J. Loweberg-DeBoer, Worldwide Adoption of Precision Agriculture Technology: The 2010 Update, Paper Presented to the 10th International Conference of Precision Agriculture, Denver, Colorado, USA, 93, 66-74 (2010)

9. E.V. Kanash, A.V. Litvinovich, A.O. Kovleva, Yu.A. Osipov, E. Salnikov. Productivity and optical characteristics of three wheat varieties (Triticum aestivum L.) and the introduction of nitrogen fertilizers. Agricultural Biology, 53, 1, 61-71 (2018)

10. E.V. Nadezhkina, Associative nitrogen fixation and productivity of photosynthesis of spring soft wheat plants under the influence of environmental conditions and fertilization Agricultural biology, 39, 3, 85-89 (2004) 